\title{
INFLUÊNCIA DE TRÊS VARIEDADES DE MILHO (ZEA MAYS, L.) E DOIS SUBSTRATOS NA PRODUÇÃO DE FORRAGEM HIDROPÔNICA
}

FRAGA, Thiago M. ${ }^{1}$

FERRARI, Lucas ${ }^{1}$

GARCIA, Anice ${ }^{2}$

LEITE, Daniel Carvalho ${ }^{3}$

TANNOUS, Simone ${ }^{4}$

Recebido em: 2009-02-02

Aprovado em: 2009-04-29

Issue DOI: $10.3738 / 1982.2278 .165$

RESUMO: O presente trabalho teve por objetivo avaliar a composição química e bromatológica da forragem de milho hidropônico para alimentação animal. A forragem foi cultivada no setor de olericultura da Faculdade "Dr. Francisco Maeda" no município de Ituverava-SP, utilizando sementes de três variedades de milho sem tratamento produzidas pela Coordenadoria de Assistência Técnica e Integral (CATI), (AL-30, AL-34 XV e AL-Bandeirante). Foram testadas três variedades em dois substratos com quatro repetições aleatoriamente em esquema fatorial. Cada tratamento foi composto por uma variedade diferente, cultivadas em dois tipo de substrato (bagaço de cana e palha de arroz), na densidade de semeadura $\left(2 \mathrm{Kg} / \mathrm{m}^{2}\right)$ e com idade de corte de 41 dias. Nas condições de clima estudadas, concluiu-se que a forragem de milho hidropônico obtida pelas três cultivares apresentou níveis considerados adequados de nutrientes e alto potencial de forragem para uso na alimentação animal, sendo que a palha de arroz produziu uma forragem de melhor qualidade.

Palavras chave: Bagaço de cana. Palha de arroz. Forragem. Hidroponia.

\section{EFFECT OF VARIETIES AND SUBSTRACTUM ON PRODUCTION AND QUALITY OF HYDROPONIC FORAGE MAYZE}

SUMMARY: The present work shows the chemical and bromatological results of maize forage under the hydroponics method for animal feeding, cultivated in the section of University "Dr. Francisco Maeda" in Ituverava-SP, using seeds of three maize varieties without treatment produced by CATI, (AL - 30, AL - 34 and AL - Bandeirante). Were tested with four repetitions in factorial plan, each treatment composed by a different variety, cultivated in two substratum type (sugarcane bagasse and rice hulls), in the sowing density $\left(2 \mathrm{Kg} / \mathrm{m}^{2}\right)$ and with age of cut of 41 days. For the climate conditions studied, it was ended that the forage of hydroponics maize obtained by the three cultivate presented adequate levels of nutrients and good forage potential for use in the animal feeding, and the rice hulls produced better quality forage.

Keywords: Sugarcane bagasse. Rice hulls. Forage. Hydroponics method.

1 Engenheiro Agrônomo. FE/FAFRAM

2 Dra. em Ciência do Solo. Docente da FE/FAFRAM - e-mail: anice@,feituverava.com.br

3 Mestrando em Genética e Melhoramento de Plantas. Faculdade de Ciências Agrárias e Veterinárias. Unesp. Jaboticabal.

4 Esp. Em Educação Ambiental. Engenheira Agrônoma. FE/FAFRAM. 


\section{INTRODUÇÃO}

Um dos problemas enfrentados pelos pecuaristas durante o inverno e em períodos de estiagem durante as épocas quentes do ano, são as condições climáticas, muitas vezes limitantes para o desenvolvimento vegetativo, ocasionando uma baixa produção e a redução do valor nutritivo da forragem das espécies nativas que ficam aquém das exigências nutricionais.

Uma alternativa é o cultivo de forragem hidropônica que é uma tecnologia de produção de biomassa vegetal, obtida através da germinação e crescimento inicial de plantas a partir de sementes viáveis (FAO, 2002). A forragem hidropônica se destaca por ser constituída por plantas de crescimento acelerado, com ciclo curto de produção, e elevado rendimento de fitomassa fresca, possuindo pouco conteúdo de fibras, alto teor protéico e boa digestibilidade, por se encontrar em fase inicial de formação, contendo grande quantidade de aminoácidos livres que serão facilmente aproveitados pelos animais (FAO, 2002; SANDIA, 2003, SANTOS et al., 2004).

Por se tratar de uma gramínea com alto desempenho na produção animal e possuir uma alta palatabilidade, tanto para ruminantes quanto para equinos, devido ao seu alto teor nutritivo, alto nível de carboidratos solúveis e alta digestibilidade, a planta de milho compõe a maioria das dietas fornecidas aos animais na produção pecuária, tanto na forma de silagem como desintegrado com palha e sabugo (JUCAFRESA, 1982; VIEIRA et al., 1980). Para ser cultivada através do sistema hidropônico, a semente de milho nova, ter elevado índice de germinação e não ser tratada com defensivos. A forragem hidropônica de milho tem boas qualidades nutricionais, é rica em proteínas e energia, além de cálcio e fósforo (AMORIM et al. 2005).

O cultivo de milho hidropônico surgiu em 1990 no Brasil, com a finalidade de servir de alimentação para equinos de raça. Após esta época, foram desenvolvidas inúmeras pesquisas que tornaram esta cultura uma alternativa de obtenção de volumosos com um alto valor proteico. Apesar do nome, esta técnica não se trata de grãos crescendo imersos em água, e sim no cultivo de alta densidade em substrato inerte sobre uma superfície lisa impermeável, constantemente umedecida com solução nutritiva (NEVES, 2001).

Esta técnica possui vantagens como, ciclo curto e continuo, isenção do uso de agrotóxicos; o desenvolvimento independe das condições agroclimáticas; dispensa investimentos em maquinários para silagem e/ou fenação e em armazenamento; requer pouca mão de obra; baixo custo de produção, e de instalação da estrutura podendo ser utilizada por pequenos produtores. O espaço e a infraestrutura são mínimas, bastando $20 \mathrm{~m}^{2} \mathrm{com}$ replantio por cabeça de gado, enquanto é preciso dispor de $1250 \mathrm{~m}^{2}$ no caso de capineira irrigada. O consumo animal de forragem hidropônica por dia é de $15 \%$ do peso vivo, onde $1 \mathrm{~kg}$ de grão produz de $7 \mathrm{a}$ $9 \mathrm{~kg}$ de forragem. O sistema de produção é muito simples e pode ser usado em qualquer época do ano e em qualquer região. Cerca de 35 dias após a semeadura, o milho está no ponto para ser fornecido aos animais. Essa rapidez torna o milho hidropônico uma excelente alternativa, especialmente nos períodos de seca prolongada. 
A produção média esperada é de 25 a $35 \mathrm{~kg} / \mathrm{m}^{2}$ de forragem hidropônica, cujo custo médio do quilo de forragem pronta é de aproximadamente US\$ 0,02 podendo ser reduzido sensivelmente se o produtor possuir milho na propriedade (GIOPLANTA, 2000). A produtividade de massa verde por ano para forragem hidropônica é de aproximadamente 7000 ton/ha para um período de 360 dias, enquanto para o mesmo período, capim elefante irrigado produz 200 ton/ha (OVINOS; CIA, 2004) e estudos têm demonstrado uma eficiência da forragem verde hidropônica, tanto em ganho de peso de animais como em produção de vacas leiteiras (FAO, 2002).

O objetivo do trabalho foi avaliar a produção e a qualidade da forragem de milho hidropônico utilizando diferentes genótipos de milho e dois tipos de substratos.

\section{MATERIAL E MÉTODOS}

O presente trabalho foi conduzido no ano agrícola de 2002, durante o período de 22 de setembro a 01 de novembro, na Faculdade "Dr. Francisco Maeda" - FAFRAM, no município de Ituverava, Estado de São Paulo, Brasil. O local encontra-se no Planalto Ocidental, na parte norte do Estado de São Paulo, apresentando como coordenadas geográficas 20²1'14 “de latitude sul, com $47^{\circ} 46^{\prime} 25$ " de latitude oeste e $713 \mathrm{~m}$ de altitude. Ituverava apresenta uma temperatura media anual de $22,8^{\circ} \mathrm{C}$, sendo a média durante o período do experimento de $27,6^{\circ} \mathrm{C}$. A precipitação média anual é de 1569,3 mm sendo a média durante o período do experimento de 128,3 mm, com as chuvas concentradas nos últimos dias.

Para a produção da forragem foi utilizado o milho (Zea mays, L.) por se tratar de uma gramínea de alta produtividade, que foi produzida através do método hidropônico, com o emprego de 2 substratos (bagaço de cana e palha de arroz).

As sementes de milho foram adquiridas na Secretaria de Agricultura e Abastecimento da cidade de Jaboticabal, sendo utilizadas três variedades distintas, todas sem tratamento fitossanitário, para servir de consumo ao gado, com as seguintes descrições: Bandeirante_(V1): pureza - 99,8\%; peneira - 100/20 L; germinação - 98\%; peso médio de 1000 sementes 273,0g. Al - 30 (V2): pureza - 99,9\%; peneira - 20 L; germinação - 92\%; peso médio de 1000 sementes - 309,5g. Al - 34 - XV (V3): pureza - 100\%; peneira - 100/20 L; germinação - 91\%; peso médio de 1000 sementes $-287 \mathrm{~g}$.

Foram testadas as três variedades, com 2 substratos e quatro repetições aleatoriamente. Foram construídos canteiros de 1,5m de comprimento por 1,0 m de largura, em terreno plano utilizando tijolo baiano em suas limitações, ficando um espaço de $0,80 \mathrm{~m}$ entre cada canteiro. Cada canteiro foi revestido por uma lona plástica, onde foram utilizados tijolos para a fixação de suas bordas (Figura 1). Antes da semeadura, as sementes foram pesadas $\left(2 \mathrm{~kg} / \mathrm{m}^{2}\right)$, para manter uma uniformidade em todos os canteiros $\left(1,5 \mathrm{~m}^{2}\right)$, sendo assim, utilizados $3 \mathrm{~kg}$ de semente por repetição e colocadas em baldes, ficando imersas em água por 24 horas, para o processo de pré-germinação, constituído de submersão em água por 24 horas, após escorrimento da água e 
repouso por mais 48 horas (Haut, 2003).

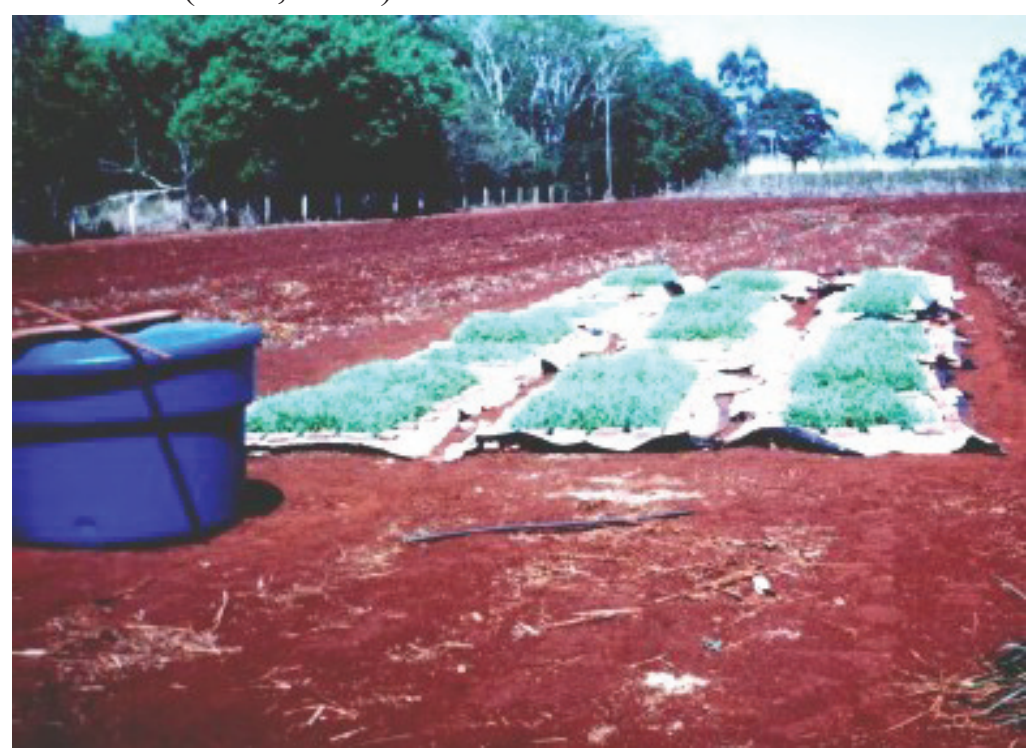

FIGURA 1. Vista geral do experimento de milho.

Em cada parcela foi colocada uma camada, de aproximadamente, $3 \mathrm{~cm}$ de bagaço de cana ou palha de arroz. Em seguida, foi feita uma irrigação para umedecer o substrato com água pura, distribuíram-se manualmente as sementes de forma mais regular possível de acordo com os tratamentos e cobriu-se com uma outra camada de $2 \mathrm{~cm}$ de substrato.

Nos 3 primeiros dias, foram feitas irrigações com auxilio de um regador utilizando somente água duas vezes ao dia. Após o terceiro dia, iniciou-se a irrigação com solução nutritiva, também sendo feita duas vezes ao dia, com duração de 12 dias, seguindo posteriormente o uso somente de água por mais 26 dias para diminuição da concentração de sais presentes na camada do substrato. Em cada irrigação foram utilizados 10 1/ $/ \mathrm{m}^{2}$.

Para preparar a solução nutritiva, foram utilizadas três soluções concentradas com a seguinte composição: Solução A (fosfato monoamônio 340 g; sulfato de magnésio 490 g; nitrato de potássio $1100 \mathrm{~g}$ ); Solução B ( nitrato de cálcio $2080 \mathrm{~g}$ ); Solução C (sulfato de magnésio: $492 \mathrm{~g}$; sulfato de cobre: $0,48 \mathrm{~g}$; sulfato de manganês: $12,48 \mathrm{~g}$; sulfato de zinco: 1,20 g; acido bórico: 6,20 g; molibdato de amônio: 0,02 g; quelato de ferro: 15,0 g). As soluções A e B, foram dissolvidas em 10 litros de água deionizada, e a solução C, dissolvida em 4 litros de água deionizada.

Nos 3 primeiros dias, foram feitas irrigações com auxílio de um regador utilizando somente água, duas vezes ao dia. Após o terceiro dia, iniciou a irrigação com soluções nutritivas, também sendo feita duas vezes ao dia, com duração de 12 dias, seguindo posteriormente o uso somente de água por mais 26 dias para diminuição da concentração de sais presente na camada do substrato. Em cada irrigação foram utilizados 10 1/ $/ \mathrm{m}^{2}$.

A colheita foi feita no dia 01 de novembro de 2002. Foi colhida uma área de $20 \times 20 \mathrm{~cm}$ de cada parcela, a que continha a planta inteira com raiz e inclusive sementes não germinadas e o substrato utilizado na semeadura. Em seguida, esse material foi seco em estufa com circulação 
de ar forçado a $55^{\circ} \mathrm{C}$ até atingir peso constante para que pudesse ser submetido às análises químicas e bromatológicas. O restante da forragem foi colhida enrolando-a como um tapete, que foi posteriormente picado e fornecido aos animais da fazenda.

As análises bromatológicas foram feitas no Laboratório de Nutrição Animal do Departamento de Zootecnia da Faculdade de Zootecnia e Engenharia de Alimentos da Universidade de São Paulo sendo que as análises da matéria seca, proteína bruta e extrato etéreo foram executadas de acordo com as normas da Association of Official Analytical Chemists (1970). Os teores de FDN, de FDA, de LDA e de LPer foram determinados conforme Goering; Van Soest (1970).

Os dados foram analisados por meio de análise de variância e teste Tukey ao nível de 5 p.100 de probabilidade, utilizando-se o pacote estatístico SAS (SAS, 1999).

\section{RESULTADOS E DISCUSSÃO}

Quando se utilizou a palha de arroz como substrato, houve alguns problemas com relação ao apodrecimento de sementes. Isto, provavelmente, ocorreu devido ao fato de que a palha de arroz (diferentemente do bagaço de cana) não absorve bem a solução colocada, fazendo com que ela ficasse empoçada em alguns locais e favorecendo o apodrecimento das sementes.

Nas Tabelas 1 a 5 estão expressos os valores obtidos na análise química feita na parte aérea das três variedades de milho produzidas no sistema de hidroponia. A Tabela 6 apresenta os teores de nutrientes adequados à cultura do milho.

TABELA 1: Composição química de macronutrientes, da parte aérea do milho, produzido por hidroponia em dois substratos diferentes (médias das três variedades).

\begin{tabular}{lcccccc}
\hline \multirow{2}{*}{ Substrato } & \multicolumn{7}{c}{ Macronutrientes $(\mathrm{g} / \mathrm{kg})$} \\
\cline { 2 - 7 } & $\mathrm{N}$ & $\mathrm{P}$ & $\mathrm{K}$ & $\mathrm{Ca}$ & $\mathrm{Mg}$ & $\mathrm{S}$ \\
\hline Bagaço de Cana & $16,20 \mathrm{a}$ & $3,24 \mathrm{a}$ & $24,80 \mathrm{a}$ & $1,86 \mathrm{~b}$ & $2,45 \mathrm{~b}$ & $1,13 \mathrm{a}$ \\
Palha de Arroz & $13,70 \mathrm{~b}$ & $2,81 \mathrm{~b}$ & $18,98 \mathrm{~b}$ & $3,30 \mathrm{a}$ & $3,27 \mathrm{a}$ & $1,07 \mathrm{a}$ \\
\hline
\end{tabular}

Medidas seguidas da mesma letra não diferem estatisticamente entre si pelo teste de Tukey $(\mathrm{P}<0,05)$

* N - Nitrogênio; P - Fósforo; K - Potássio; Ca - Cálcio; Mg - Magnésio; S - Enxofre;

TABELA 2: Composição química de micronutrientes, da parte aérea do milho, produzido por hidroponia em dois substratos diferentes (médias das três variedades).

\begin{tabular}{cccccc}
\hline \multirow{2}{*}{ Substrato } & \multicolumn{5}{c}{ Micronutrientes $(\mathrm{g} / \mathrm{kg})$} \\
\cline { 2 - 6 } & $\mathrm{B}$ & $\mathrm{Cu}$ & $\mathrm{Fe}$ & $\mathrm{Mn}$ & $\mathrm{Zn}$ \\
\hline Bagaço de Cana & $15,08 \mathrm{a}$ & $5,41 \mathrm{a}$ & $1754,16 \mathrm{a}$ & $102,83 \mathrm{a}$ & $22,66 \mathrm{a}$ \\
Palha de Arroz & $17,25 \mathrm{a}$ & $4,58 \mathrm{a}$ & $1976,00 \mathrm{a}$ & $58,75 \mathrm{~b}$ & $15,08 \mathrm{~b}$ \\
\hline
\end{tabular}

Medidas seguidas da mesma letra não diferem estatisticamente entre si pelo teste de Tukey $(\mathrm{P}<0,05)$

B - Boro; Cu - Cobre; Fe - Ferro; Mn - Manganês; Zn - Zinco 
TABELA 3: Composição química de macronutrientes, da parte aérea do milho, produzido por hidroponia para as três variedades estudadas (médias dos dois substratos).

\begin{tabular}{ccccccc}
\hline \multirow{2}{*}{ Variedades } & \multicolumn{7}{c}{ Macronutrientes $(\mathrm{g} / \mathrm{kg})$} \\
\cline { 2 - 7 } & $\mathrm{N}$ & $\mathrm{P}$ & $\mathrm{K}$ & $\mathrm{Ca}$ & $\mathrm{Mg}$ & $\mathrm{S}$ \\
\hline 1 & $14,62 \mathrm{a}$ & $3,22 \mathrm{a}$ & $19,50 \mathrm{a}$ & $2,70 \mathrm{a}$ & $2,75 \mathrm{a}$ & $1,17 \mathrm{a}$ \\
3 & $15,41 \mathrm{a}$ & $3,00 \mathrm{a}$ & $21,46 \mathrm{a}$ & $2,37 \mathrm{a}$ & $3,10 \mathrm{a}$ & $1,07 \mathrm{a}$ \\
& $14,82 \mathrm{a}$ & $2,86 \mathrm{a}$ & $24,71 \mathrm{a}$ & $2,37 \mathrm{a}$ & $2,75 \mathrm{a}$ & $1,06 \mathrm{a}$ \\
\hline
\end{tabular}

Medidas seguidas da mesma letra não diferem estatisticamente entre si pelo teste de Tukey $(\mathrm{P}<0,05)$

TABELA 4: Composição química de micronutrientes, da parte aérea do milho, produzido por hidroponia para as três variedades estudadas (médias dos dois substratos).

\begin{tabular}{cccccc}
\hline \multirow{2}{*}{ Variedades } & \multicolumn{5}{c}{ Micronutrientes $(\mathrm{g} / \mathrm{kg})$} \\
\cline { 2 - 6 } & $\mathrm{B}$ & $\mathrm{Cu}$ & $\mathrm{Fe}$ & $\mathrm{Mn}$ & $\mathrm{Zn}$ \\
\hline 1 & $15,00 \mathrm{a}$ & $5,50 \mathrm{a}$ & $1783,75 \mathrm{a}$ & $76,50 \mathrm{a}$ & $18,87 \mathrm{a}$ \\
2 & $17,50 \mathrm{a}$ & $5,25 \mathrm{a}$ & $1807,87 \mathrm{a}$ & $86,75 \mathrm{a}$ & $19,37 \mathrm{a}$ \\
3 & $16,00 \mathrm{a}$ & $4,25 \mathrm{a}$ & $2003,62 \mathrm{a}$ & $79,12 \mathrm{a}$ & $18,37 \mathrm{a}$ \\
\hline
\end{tabular}

Medidas seguidas da mesma letra não diferem estatisticamente entre si pelo teste de Tukey $(\mathrm{P}<0,05)$

Pode-se observar que o Nitrogênio foi o único elemento em que houve interação entre substrato e variedades. A Tabela 5 mostra esta interação.

TABELA 5: Medidas estimadas do desdobramento dos teores de nitrogênio na interação entre substrato e variedades

\begin{tabular}{l|c|c|c}
\hline \multicolumn{1}{c}{ Substrato } & \multicolumn{3}{c}{ Nitrogênio } \\
\cline { 2 - 4 } & Variedade 1 & Variedade 2 & Variedade 3 \\
\hline Bagaço de Cana & $14,75 \mathrm{~b}$ & $17,67 \mathrm{a}$ & $16,20 \mathrm{ab}$ \\
Palha de Arroz & $14,50 \mathrm{a}$ & $13,15 \mathrm{a}$ & $13,45 \mathrm{a}$ \\
\hline
\end{tabular}

Medidas seguidas da mesma letra não diferem estatisticamente entre si pelo teste de Tukey $(\mathrm{P}<0,05)$

TABELA 6: Faixa de teores de nutrientes adequados: milho

\begin{tabular}{|c|c|c|c|c|c|c|}
\hline Macro & $\mathbf{N}$ & $\mathbf{P}$ & K & $\mathrm{Ca}$ & $\mathrm{Mg}$ & $\mathbf{S}$ \\
\hline $\mathbf{g} / \mathbf{K g}$ & $27-35$ & $2.0-4.0$ & $17-35$ & $2.5-8.0$ & $1.5-5.0$ & $1.5-3.0$ \\
\hline Micro & B & & & & Mn & $\mathrm{Zn}$ \\
\hline $\mathbf{g} / \mathbf{K g}$ & $10-25$ & & & & $0-200$ & $15-100$ \\
\hline
\end{tabular}

* Fonte: EMBRAPA. (1999)

A comparação feita entre os valores observados nas Tabelas 1 a 4 para a análise de composição química da parte aérea e os valores adequados para faixas de teores de nutrientes, conforme a Tabela 5 permitem as seguintes observações:

O nitrogênio apresentou um teor inferior ao considerado adequado, porém houve diferença entre os dois substratos sendo que o teor de nitrogênio das plantas cultivadas em bagaço de cana foi maior do que naquelas cultivadas em palha de arroz. Já entre as três variedades não houve diferenças entre os níveis de nitrogênio. 
$\mathrm{O}$ fósforo apresentou-se em teores adequados nas três variedades, e também quando utilizou-se bagaço de cana como substrato, esse teor foi maior. Esse comportamento foi observado também para potássio.

Com relação aos macronutrientes secundários, cálcio e magnésio apresentaram-se em teores adequados, porém as plantas cultivadas na palha de arroz apresentaram teores maiores desses dois nutrientes, não tendo havido diferenças entre variedades. Já o enxofre, em todas as variedades, apresentou teores menores que os considerados adequados, e não houve diferença entre os dois substratos.

Com relação aos micronutrientes, todos apresentaram em teores considerados adequados e a única diferença significativa entre os substratos foi em relação ao manganês e ao zinco, para os quais, quando utilizou-se bagaço de cana como substrato os teores foram superiores. Chama a atenção os elevados teores de ferro encontrados na análise, o que provavelmente está relacionado com a forma em que este nutriente foi oferecido (quelato) e talvez pelo fato da planta ser uma gramínea, em que a redução de $\mathrm{Fe}^{3+}$, para $\mathrm{Fe}^{2+}$ (forma normalmente absorvida pelas plantas) acontece com certa facilidade. Entretanto esses altos teores não prejudicariam um animal que se alimentasse desse volumoso, visto que ele seria eliminado do seu organismo sem problemas (MELLO, 2003) ${ }^{5}$.

Embora praticamente todos os nutrientes tenham estado dentro do nível adequados para plantas de milho, o substrato bagaço de cana apresentou-se superior em relação aos teores observados nas plantas de macronutrientes primários e de alguns micronutrientes, enquanto que com relação aos micronutrientes secundários a palha de arroz foi melhor.

A composição bromatológica de um alimento é o ponto de partida para se avaliar seu valor nutritivo para os animais. Diversos autores enfatizam que a composição em nutrientes da planta de milho pode variar de acordo com o método de cultivo utilizado, a proporção de grãos, as condições edafo-climáticas, a idade e/ou altura de corte, e, principalmente em função do cultivar (JUCAFRESA 1982; VALENTE et al. 1984; ANDRADE et al., 1998).

As principais frações do alimento que devem ser obtidas em uma análise bromatológica são:

MATÉRIA SECA(MS): representa o peso do material analisado totalmente livre de água, extraída num processo de secagem. É um dado de extrema importância, principalmente, quando obtido de alimentos volumosos, que normalmente apresentam umidade variável. Os valores de matéria seca facilitam a comparação qualitativa dos diversos nutrientes, entre diferentes alimentos. A composição dos alimentos em Tabelas, o cálculo das necessidades dos animais e o consumo de alimentos são expressos em termos de matéria seca.

PROTEÍNA BRUTA (PB): o requerimento proteico, assim como o energético, é de fundamental importância para bovinos. A deficiência de um ou de ambos limitará a produção animal. A proteína, normalmente, é suplementada através dos concentrados. Portanto, para que ocorra uma suplementação adequada de um balanceamento correto da dieta, torna-se necessário

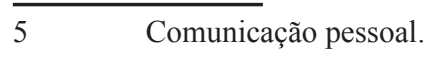

Nucleus Animalium, v.1, n.1, maio 2009 
o conhecimento do real valor nutritivo.

FIBRAS: as metodologias utilizadas para determinar os valores de fibra dos alimentos são: fibra bruta (FB), Fibra em Detergente Neutro (FDN), fibra em Detergente Ácido (FDA). Estes valores relacionam-se com a idade da forragem, pois quanto maior a percentagem de fibra, menor a qualidade da forragem, podendo limitar o consumo de matéria seca e Energia.

EXTRATO ETÉREO (EE): determina a percentagem de gordura dos alimentos sendo útil para quantificar energia. Os alimentos com altos teores de gorduras têm altos valores de NDT (Nutrientes digestíveis totais), pelo fato das gorduras fornecerem 2,25 vezes mais energia quando comparadas aos carboidratos e proteínas.

MATÉRIA MINERAL (MM): é utilizada para estimar a fração bruta de minerais do alimento e também para verificar contaminação na amostra, através de compostos que não fazem parte da fração nutritiva do alimento (solo, metais, etc.).

EXTRATIVOS NÃO NITROGENADOS (ENN): é um valor calculado a partir da soma de PB, FB, EE e MM, expressos em termos de MS e subtraído de 100. Representa os carboidratos de mais fácil digestão, como os açúcares e o amido.

A Tabela 7 mostra os valores obtidos na análise bromatológica da parte aérea do milho no sistema hidropônico nas três variedades.

TABELA 7: Composição bromatológica da parte aérea do milho produzido por hidroponia, apresentada pelas três variedades diferentes em 2 substratos.

\begin{tabular}{|l|c|c|c|c|c|c|}
\hline \multirow{2}{*}{\multicolumn{1}{|c|}{ VARIEDADES }} & MS & PB & FB & EE & MM & ENN \\
\cline { 2 - 8 } & \multicolumn{7}{|c|}{$(\%)$} \\
\hline Palha arroz/AL-Band. & 94,43 & 12,22 & 23,21 & 2,93 & 15,57 & 46,07 \\
\hline Palha arroz/AL-30 & 94,06 & 15,81 & 20,41 & 2,74 & 11,83 & 49,21 \\
\hline Palha arroz/AL-34-XV & 94,23 & 15,09 & 23,01 & 3,48 & 13,74 & 44,68 \\
\hline Bagaço Cana/AL-Band. & 93,73 & 10,50 & 27,96 & 3,52 & 8,83 & 49,19 \\
\hline Bagaço Cana/AL 30 & 94,33 & 11,49 & 23,78 & 3,65 & 9,16 & 51,92 \\
\hline Bagaço Cana/AL 34-XV & 94,33 & 11,57 & 26,78 & 3,65 & 8,53 & 49,47 \\
\hline
\end{tabular}

* MS - matéria seca; PB - proteína bruta; FB - fibra bruta; EE - estrato etéreo; MM - matéria mineral; ENN extrativos não nitrogenados.

Os teores de matéria seca nos 6 tratamentos foram semelhantes e similares ao obtido por Amorim (1999) que foi de 90\%.

Os valores médios de PB encontrados no presente estudo da parte aérea da planta de milho produzida por hidroponia foram um pouco superiores, quando as variedades foram cultivadas na palha de arroz do que quando foram cultivadas em bagaço de cana os valores em palha de arroz encontrados neste trabalho foram superiores aos observados por Pereira et al. (2003) para milho em palha de arroz. A cultivar AL-Band. apresentou valores inferiores de 
proteína bruta, independente do substrato. Os valores em bagaço de cana foram inferiores ao obtido por Amorim (1999) que foi de 13,1\%, mas superiores ao obtido por Andrade et al.(1998), de $9,2 \%$ que trabalhou com 7 cultivares de milho para silagem cortado a 15 e $50 \mathrm{~cm}$ acima do solo.

$\mathrm{Na}$ formulação de dietas alimentares, a importância do teor de proteína decorre de sua essencialidade direta para o organismo animal, para fins de manutenção e produção de carne e leite, assim como de forma indireta, via atividade da microbiota ruminal (Paulino, 1999). Embora seja exigido o mínimo de 7\% de PB para garantir a fermentação dos carboidratos estruturais no rúmen, um valor mais alto é necessário para o atendimento das exigências proteicas do organismo animal (VAN SOEST; MERTENS, 1984). Os requerimentos de proteína bruta para novilhos em engorda $11 \%$ PB e vacas de $500 \mathrm{~kg}$ PV produzindo leite até $17 \mathrm{~kg}$, diariamente, com 4\% de gordura, são de 14\% de PB (NRC, 1989 e 1996).

O teor de fibra bruta foi $15 \%$ menor para a variedade AL-30 em relação as variedade AL-34 e AL-Bandeirantes, porém as três foram superiores aos valores de 20 e 16,7 \% obtidos para este parâmetro por Vieira et al. (1980) e FAEC (2004), respectivamente. Com relação ao substrato, os valores médios de fibra bruta (FB) foram um pouco superiores, quando as variedades foram cultivadas no bagaço de cana do que quando foram cultivadas na palha de arroz. Como, quanto maior a percentagem de fibra, menor a qualidade da forragem, a forragem produzida em bagaço é de menor qualidade. Esses altos teores de fibra bruta apresentados pelo material podem ser explicados pelo fato de que analise bromatológica é feita do material todo (planta +substrato), o que explica também a diferença apresentada entre os substratos.

O teor de extrato etéreo somente a variedade AL-Bandeirantes não apresentou diferença quando cultivada em substratos diferentes. As outras variedades produziram maior teor de extrato etéreo quando cultivadas em bagaço de cana do que em palha de arroz. Todos os valores de extrato etéreo foram superiores ao obtido por Amorim (1999), que foi de 1,8\%.

Já os teores de material mineral variaram nas três variedades, e foram maiores quando o substrato usado foi a palha de arroz. Comparando-se aos valores obtidos por Amorim (1999), os valores de material mineral em palha de arroz foram superiores e os valores em bagaço de cana inferiores, aos obtidos por aquele autor (cerca de 11\%).

Com relação a presença de carboidratos de mais fácil digestão, como os açúcares e o amido, representados pelos valores de ENN, observam-se valores muito semelhantes nos tratamentos, somente salientando-se a variedade AL-30 como ligeiramente superior.

A Tabela 8 mostra a composição bromatológica média de outras forragens normalmente usadas para consumo animal. 
TABELA 8: Composição bromatológica média de outros alimentos normalmente usadas para consumo animal.

\begin{tabular}{|c|c|c|c|c|c|c|c|}
\hline \multirow{2}{*}{ Ingredientes } & \multicolumn{4}{|c|}{ Forragens Verdes } & \multicolumn{3}{c|}{ Volumosos Secos } \\
\cline { 2 - 8 } & $\begin{array}{c}\text { Milho } \\
\text { Verde }\end{array}$ & Sorgo & $\begin{array}{c}\text { Cana de } \\
\text { Açúcar Madura }\end{array}$ & $\begin{array}{c}\text { Capim } \\
\text { elefante }\end{array}$ & $\begin{array}{c}\text { Milho } \\
\text { palha seca }\end{array}$ & $\begin{array}{c}\text { Sorgo } \\
\text { forragem } \\
\text { seca }\end{array}$ & $\begin{array}{c}\text { Capim } \\
\text { elefante } \\
\text { seco }\end{array}$ \\
\hline PB\% & 2 & 1,5 & 1,9 & 2,6 & 2,5 & 6,2 & 6,9 \\
\hline FB\% & 5,1 & 6,6 & 8,9 & 6 & 28,2 & 25,1 & 34 \\
\hline MM\% & 1,2 & 2 & 1,8 & 1,9 & 2,9 & 7,1 & 9,8 \\
\hline
\end{tabular}

Fonte: Ovinos \& Cia (2004)

Comparando-se a forragem de milho hidropônico com as outras, comumente usadas, percebe-se o maior valor de cada um dos componentes da composição bromatológica, indicando ser uma alternativa bastante interessante para alimentação animal, quando necessitar rapidamente de alimento e em especial em período de estiagem prolongada.

\section{CONCLUSÃO}

A composição bromatológica para as três variedades, AL - BANDEIRANTE, AL - 30 e $\mathrm{AL}-34 \mathrm{XV}$, apresentaram níveis considerados adequados para a consumo animal e superiores aos observados em outros tipos de forragens.

Não houver variações em relação os teores nutrientes entre as três variedades, podendo considerar que todas apresentaram níveis adequados.

Assim, o milho hidropônico obtido pelas três cultivares apresentou boa concentração de nutrientes, e bom potencial na produção de forragens para uso na alimentação de animais, representando uma alternativa, quando se enfrenta problemas com veranicos, solos empobrecidos, falta de espaço e outros que o pequeno produtor pode enfrentar.

A palha de arroz demonstrou ser uma forragem de melhor qualidade, levando-se em conta os teores de proteína bruta e fibra bruta, e desde que tomados os devidos cuidados com relação ao manejo (umidade), deve ser considerada como opção, principalmente pela facilidade de obtenção e o custo praticamente nulo nas regiões produtoras de arroz.

Sugere-se a aplicação da tecnologia em outros substratos, principalmente nos encontrados com facilidade em cada região, para minimizar custo de produção.

\section{AGRADECIMENTOS}

À Empresa GIOPLANTA pelo fornecimento da solução nutritiva. 


\section{REFERÊNCIAS}

AMORIM, A. C. Produção, composição e degradabilidade em caprinos, de milho produzido por hidroponia. 1999. 68 p. Trabalho de Conclusão de Curso. Universidade Estadual Paulista. Faculdade de Ciências Agrária e Veterinári. Jaboticabal.

ANDRADE, J. B. et al. Produção de silagem e reciclagem de nutrientes em milho. I - produção de matéria seca e composição bromatológica. Boletim da Indústria Animal, Nova Odessa, v. 55, n.1, p. 51-56, 1998.

EMBRAPA - Empresa Brasileira de Pesquisa Agropecuária. Comunicação para Transferência de Tecnologia. Manual de análises química de solo, plantas e fertilizantes. Brasília, 1999. $370 \mathrm{p}$

FAO. Forraje verde hidropónico. Manual Técnico. TCP/ECU/066. Santiago-Chile, 2001. Disponível: http://www.fao.org/Regional/LAmerica/prior/segalim/pdf/1.pdf. Acesso: 03 jul. 2004.

FAEC- FEDERAÇÃO DE AGRICULTURA E PECUÁRIA DO ESTADO DO CEARÁ. 2004. Alternativa alimentar de baixo custo e alta qualidade. In: www.faec.org.br/forragemhidroponica.htm. Data de acesso: 10 fev. 2004.

GIOPLANTA. Forragem hidropônica. 2000. Disponível em: http://www.brasil.terravista.pt / ipanema/3555/forrage2.htm . Acesso em: 20 mar.2004.

HAUT, V. Produção de forragem hidropônica de gramíneas. 2003, 94f. Dissertação (Mestrado em Agronomia)- Universidade Federal de Santa Maria.

JUCAFRESA, B. Forragens: fertilização, características e valor nutritivo. Litexa., 1982. p. 163-172.

NEVES, A.L.R.A. Milho hidropônico para alimentação de animais. Tecnologia e Treinamento Agropecuário, Viçosa: CPT. 2001. 46p.

NRC - National Research Council . Nutrient Requirements of Dairy Cattle. Washington: National Academy of Sciences, 1989.

NRC - National Research Council. Nutrient Requirements of Beef Cattle. Washington: 
National Academy of Sciences, 1996.

OVINOS \& Cia. Forragem hidropônica de milho. Disponivel: http://www.ovinosecia.com. br/ . Acesso em: 03 jul. 2004.

PAULINO M.F. Estratégias de suplementação para bovinos em pastejo. In: SIMPÓSIO DE PRODUÇÃO DE GADO DE CORTE, 1. Anais... UFV: Viçosa, 1999. p.137-156.

PEGORIM, E. Grãos e flores produzidos a partir do esgoto. 2004. Revista Ciência Hoje Online. In: http://cienciahoje.uol.com.br/controlPanel/materia/view/1370. Acesso em 04 jul. 2006.

PEREIRA, R. C. Produção de milho fertirrigado em diferentes tipos de substratos. In: REUNIÃO ANUAL DA SOCIEDADE BRASILEIRA DE

ZOOTECNIA, 40. Anais... Santa Maria, 2003 (CD-ROM).

SANDIA- Sandia Nacional Laboratorios para New México y el Caribe. Producción de forraje verde hidropónico. Disponível em: www.sandia.gov/water/USMBpress/ gallegosagricultura.pdf Acesso em: 06 set.2003.

SANTOS O.S. et al. Produção de forragem hidropônica de cevada e milho e seu uso na alimentação de cordeiros. Santa Maria: UFSM/CCR, Santa Maria, 2004. 8p. (Informe Técnico).

VALENTE, J. O.; SILVA, J. F. C.; GOMIDE, J. A.. Estudo de duas variedades de milho (Zea mays, L.) e de quatro variedades de sorgo para silagem. 1. Produção e composição do material ensilado e das silagens. Rev. Soc. Bras. Zootec., v.13, n.1, p.74-81, 1984.

VAN SOEST, P.J. E MERTENS, D.R. The use of neutral detergent fiber versus acid detergent fiber in balancing dairy rations. Proc. Technical Symposium Monsanto. Nutrition Chemicals Division. p.75-92, 1984.

VIEIRA, P.F., FARIA, V.P, ANDRADE, P. Valor nutritivo de silagem de três variedades de milho. Rev. Soc. Bras. Zootec., v.9, n.1, p.159-70, 1980. 